Estudios Constitucionales, Año 11, No 1, 2013, pp. 477 - 510.

ISSN 0718-0195

Centro de Estudios Constitucionales de Chile Universidad de Talca

"Indulto Particular: Perfeccionamiento de una Institución Arcaica hacia

la Protección de Derechos Fundamentales"

Juan Pablo Beca Frei

\title{
INDULTO PARTICULAR: PERFECCIONAMIENTO DE UNA INSTITUCIÓN ARCAICA HACIA LA PROTECCIÓN DE DERECHOS FUNDAMENTALES*
}

\section{PRESIDENTIAL PARDON: IMPROVEMENT OF AN ANCIENT LEGAL INSTRUMENT TOWARDS THE PROTECTION OF FUNDAMENTAL RIGHTS}

Juan Pablo Beca Frei*

Universidad Católica de Temuco

jbeca@uct.cl

RESUMEN: El indulto es una facultad presidencial de antiquísima data y de tradicional desarrollo en nuestro país, que al ser una facultad discrecional propende a la vulneración de derechos fundamentales, asi como a la posible infracción a normas de derecho internacional, de ahi que esta institución ha traido nefastas consecuencias en la aplicación de justicia, fenómeno que ocurre generalmente cuando dicha facultad es ejercida de manera abusiva.

Consecuentemente con lo expuesto, se desarrolla un análisis critico respecto de las ventajas y desventajas que presenta este instituto, teniendo como eje las actuales exigencias del Estado de Derecho en relación al respeto a los derechos fundamentales, lo que nos ha instado como grupo a proponer el debate respecto de la legislación existente en la materia.

Con tal propósito, este trabajo presenta una innovadora propuesta que busca hacer más transparente el ejercicio de esta facultad, con la finalidad de generar equidad y contribuir al bien común de nuestra sociedad.

ABSTRACT: A pardon is a presidential power of ancient data and traditional development in our country, being a discretionary power tends to the violation of fundamental rights as well as the possible infringement of international law, hence this legal instrument has brought harmful consequences in the application of justice, a phenomenon that usually occurs when such power is improperly exercised.

According with what has been explained a critical analysis is developed concerning the advantages and disadvantages of this legal instrument, focusing on the present requirements of the Rule of Law in relation to the respect for fundamental rights, which has urged us to call for a debate on the existing legislation on the subject.

\footnotetext{
* Trabajo realizado junto a los egresados de Derecho de la Universidad Católica de Temuco: Juan Manuel Arias, Juan Carlos Guajardo Puga, Graciela Hermosilla Riobó, Mical Mena Oliva y Álvaro Vidal Bastías. Trabajo recibido el 27 de septiembre de 2012 y aprobado el 26 de diciembre de 2012.

* Magíster en Derecho, Università degli studi di Genova. Magíster en Derecho mención Derecho Constitucional, Universidad Católica de Temuco. jbeca@uct.cl
} 
In order to achieve that goal, this work presents a modern proposal, which expects to increase transparency in the exercise of this power, so that generates equity and contributes to the common good of oursociety.

Palabras ClaVE: Indulto particular, Estado de Derecho, Derechos Fundamentales.

KEY WORDS: Presidential pardon, Rule of Law, Fundamental Rights.

\section{INTRODUCCIÓN}

El trabajo que a continuación presentamos se centra en un análisis a la institución jurídica del indulto particular o presidencial, a través de su estudio pretendemos demostrar que necesita de innovaciones, tanto en su aspecto formal como de fondo, puesto que su permanencia en nuestro Derecho de la manera en que actualmente se encuentra consagrado, da margen a potenciales vulneraciones a los derechos fundamentales contenidos en nuestra Carta Fundamental, así como en los Tratados Internacionales ratificados por Chile y que se encuentren vigentes.

En un Estado de Derecho no se justifica la existencia de una facultad presidencial meramente discrecional en lo relativo a la concesión de indultos particulares, dadas las perniciosas consecuencias que puede acarrear tanto para la convivencia social como para la seguridad jurídica, sin que exista un debido mecanismo de control como los contemplados en distintos Estados del orbe, de los cuales tomaremos referencias en el desarrollo de nuestro trabajo a modo de adecuar la institución a la normativa internacional y del Derecho Comparado vigentes.

Realizamos la presente investigación partiendo por la génesis del instituto hasta su permanencia en los distintos ordenamientos jurídicos, acotándola al indulto particular propiamente tal, por ser ese tipo de indulto una facultad privativa del Presidente de la República, encontrándose al margen del control del legislador, el que provoca los problemas a los que hacíamos referencia.

A partir de lo expuesto pretendemos realizar un estudio acabado de la institución que comprenda su regulación en el Derecho Comparado como así también, sus aspectos positivos y negativos, a fin de lograr un amplio conocimiento de ella, que en definitiva nos permita elaborar una propuesta seria y con altura de miras en torno a tan controvertida figura.

\section{Capítulo I}

INDULTO PARTICULAR Y SU RELACIÓN CON LOS DERECHOS FUNDAMENTALES

\section{El indulto}

El indulto particular o presidencial ha sido reconocido en Chile como una de las instituciones más antiguas y tradicionales de nuestra legislación, recogida 
del viejo Derecho español y del indiano, que continúa vigente en el nuestro. Tal facultad, radicada en el Presidente de la República, denota sesgos de un sistema presidencialista de gobierno, dentro del cual encontramos remembranzas de lo que alguna vez fue la monarquía absoluta.

El indulto ${ }^{1}$ particular es una petición garantizada constitucionalmente, teniendo derecho todo ciudadano a solicitarlo. Su otorgamiento se realiza a través de un acto administrativo, que en virtud de la Constitución le corresponde al Presidente de la República, adquiriendo la forma de un decreto supremo, el que debe ser firmado por el Ministro de Justicia. A su vez, es un acto de gobierno discrecional; acto de gobierno porque se trata de una facultad constitucional directa que representa los intereses generales de la nación y es discrecional porque el Presidente puede conceder o no libremente el indulto sin tener que consultar a ninguna autoridad o persona, siendo irrelevante la opinión del condenado que lo solicita, sin que procedan recursos jurisdiccionales en contra de su concesión o denegación.

De lo anterior deriva la necesidad de que facultades como ésta, en la práctica, excesivas e incompatibles con nuestro desarrollo jurídico, sean modificadas o derechamente suprimidas, debido a que presenta elementos característicos de una forma de gobierno no democrática, siendo una institución excepcional y potencialmente vulneradora del actual sistema constitucional y procesal, asimismo, su permanencia puede atentar contra determinados derechos fundamentales ${ }^{2}$, tópico del que nos ocuparemos a continuación.

\footnotetext{
${ }^{1}$ El indulto es una causal de extinción de la responsabilidad penal, regulada como tal en el Código Penal, el que puede ser definido como aquel perdón proveniente del Estado, que exime al beneficiado del cumplimiento de la pena a que hubiese sido condenado, sin por ello ser borrado el delito ni sus efectos penales y extrapenales. La gran diferencia que tiene el indulto con otras formas legales es que sólo condena o modifica la pena del beneficiado y no le quita el carácter de condenado para efectos de la reincidencia, es decir, que si vuelve a delinquir no es posible que el juez aplique en su favor la atenuante de irreprochable conducta anterior o si se da el caso, no podrá aplicar una pena alternativa, salvo la reclusión nocturna. VARGAS (1994), p. 55.

${ }^{2}$ La expresión "Derechos Fundamentales" corresponde en cierto modo a un concepto moderno que ha sido utilizado con mayor frecuencia sólo en los últimos años, habiendo sido desplazado por mucho tiempo por el concepto de "Derechos Humanos" por su mayor popularidad en el mundo cotidiano. Empero, el concepto que consideramos más adecuado es el de Derechos Fundamentales, primeramente, porque la expresión Derechos Humanos es un término ambiguo debido a los diversos significados que se le han dado a la expresión con el transcurso del tiempo y, además, porque la mencionada expresión apunta al titular de los derechos, que sería propiamente el ser humano y al ser éste el principal titular de derechos podría conducir a inconsistencias absurdas como considerar como Derecho Humano al simple derecho al pago del precio, por la sola razón de que su titular es un ser humano. Alexy (2001), pp. 388-398.
} 


\section{Derecho a la Vida}

En general, es posible vincular al indulto con distintos derechos fundamentales, dependiendo de la perspectiva desde la cual se trate el tema. Así, del análisis del catálogo de derechos fundamentales contemplado en nuestra Constitución y en los diversos tratados internacionales ratificados por nuestro país, es posible constatar que se le ha concebido como una vía para resguardar el derecho a la vida, particularmente, si la concesión de un indulto evita la aplicación de la pena de muerte, sanción que se encuentra en franca retirada en las naciones civilizadas, a excepción de los Estados Unidos. Lo anterior se ve ratificado por numerosas disposiciones que configuran el sistema de protección universal del derecho a la vida y repudio a la pena de muerte, tales como el artículo $3^{\circ}$ de la Declaración Universal de los Derechos Humanos de 1948, el artículo 6º del Pacto Internacional de Derechos Civiles y Políticos de 1966, y el artículo $4^{\circ}$ de la Convención Americana sobre Derechos Humanos de 1969.

De las disposiciones señaladas, se desprende que sólo se permitiría indultar en forma parcial a condenados por delitos de lesa humanidad, esto es, conmutar o reducir su pena, pues de esta forma se concilia en la práctica la tendencia generalizada a la abolición de la pena capital con la necesidad de mantener la sanción penal para estos criminales, todo dentro del contexto del moderno derecho internacional.

En suma, en relación al derecho fundamental a la vida podemos concluir que el indulto, puede beneficiarlo directamente cuando se trata de dejar sin aplicación la pena de muerte, pero por otro lado podría eventualmente afectarlo indirectamente si es que se beneficia con él a culpables del delito de homicidio, especialmente a autores de crímenes de lesa humanidad, puesto que se debilitaría la sanción penal de conductas que importan el atentado más grave que pueda concebirse en contra de la vida.

\section{Principio General de Libertad y Derecho a la Honra de la Persona y su Familia}

Una relación similar a la que se expuso a propósito del derecho fundamental a la vida se da con respecto al principio general de libertad en su manifestación específica de libertad ambulatoria, ya que el indulto normalmente importará la concesión de libertad si es total, o acelerará su alcance tratándose de un indulto parcial; mientras que, por otro lado, siempre se estará afectando a la víctima del delito, quien podrá ver lesionada su honra u otros derechos garantizados constitucionalmente como la inviolabilidad del hogar (artículo 19 número 5 Constitución 
Política de la República) y la propiedad (artículo 19 número 24 Constitución Política de la República), o bien otros bienes jurídicos dependiendo del delito. En nuestro medio, cuando se debate sobre el indulto, una de las mayores tensiones que se genera es la vinculación con la posibilidad de que mediante este instrumento jurídico se beneficie a ex militares condenados por violaciones de derechos humanos cometidas durante el régimen militar entre los años 1973 y 1988. En efecto, históricamente, se ha tratado de justificar el indulto con la necesidad de atender graves exigencias de interés público, entre las que cabe destacar las de carácter político, exigencias que hacen imperativo un llamado a la concordia colectiva; en consecuencia, cabe preguntarse si el indulto cumple en la especie con esta finalidad, o si por el contrario contribuye a abrir antiguas heridas del pasado que pueden llegar a convertirse en obstáculos insalvables para el proceso de reconciliación y democracia nacional. Por otro lado, cabe preguntarse si un indulto en estos casos vulneraría tratados internacionales que buscan evitar la impunidad de las violaciones de derechos humanos y/o delitos de lesa humanidad, cuestión sobre la que volveremos más adelante.

Por lo anterior, es que, a nuestro parecer, de indultarse a estos criminales se afectaría de forma incalculable el derecho a la honra de la persona y su familia, constitucionalmente garantizado en el artículo 19 número 4 de nuestra Constitución, así como la dignidad de los familiares de las víctimas de derechos humanos, lo que además de conectarse con los compromisos internacionales adquiridos por Chile frente a la comunidad internacional y a los argumentos que tratan de justificar el indulto, nos transporta de inmediato al campo jurídico escasamente explorado en nuestra doctrina y jurisprudencia, correspondiente a la responsabilidad del Estado por actividad lícita en esta materia y el consiguiente resarcimiento del daño moral desproporcionado, grave, injusto e irrazonable ocasionado al honor de los particulares.

\section{Debido proceso}

Es generalmente reconocido en doctrina y jurisprudencia el hecho de que la expresión "Debido proceso" adolece de gran vaguedad; así, para muchos no es más que una denominación común que agruparía a un conjunto de derechos específicos consagrados en tratados internacionales como la Convención Americana de Derechos Humanos (artículo $8^{\circ}$ ) y el Pacto Internacional de Derechos Civiles y Políticos (artículo 14), entre los que se hayan: la presunción de inocencia y el derecho a ser juzgado dentro de un plazo razonable por un tribunal establecido con anterioridad a la perpetración del hecho y no por comisiones especiales. En 
este contexto, el debido proceso ha sido definido como "el derecho que garantiza al ciudadano la realización en el proceso de los principios, derechos y garantías procesales constitucionalizadas" (BANDRÉs, 1992, p. 111).

Una de las críticas más importantes que se hacen al indulto, y que ha sido evidenciada por autores como Juan Enrique Vargas, consiste en que importa una flagrante intervención de los Poderes Legislativo y Ejecutivo en el Poder Judicial, ya sea mediante una ley de indulto general en el primer caso, e indulto particular en el segundo. Al hacer el Presidente de la República uso de su facultad constitucional de indultar en forma particular, inevitablemente altera lo establecido por sentencia ejecutoriada en un proceso penal legalmente tramitado tendiente al aseguramiento de un resultado justo y equitativo, con respeto a las garantías de ambas partes involucradas en el mismo; es decir, en definitiva lo que hace de cierta forma es actuar en contra del debido proceso, consagrado como garantía procesal en el artículo 19 número 3 inciso sexto de nuestra Carta Fundamental.

\section{Seguridad jurídica}

Aun cuando la seguridad jurídica en sentido subjetivo, entendida como la certeza o confianza acerca de cómo ocurrirán las cosas reguladas por el ordenamiento jurídico, no constituya de acuerdo a la concepción tradicional un derecho fundamental, sino más bien uno de los valores jurídicos pilares del derecho, nos ha parecido relevante tratarla en este trabajo. La intervención legislativa o ejecutiva desplegada con el fin de modificar decisiones judiciales implica una franca violación, amparada por nuestro sistema jurídico, a la institución de la cosa juzgada, una de las manifestaciones positivas más palmarias de la seguridad jurídica. En consecuencia, antes del otorgamiento de un indulto, ha de sopesarse si las razones de bien común esgrimidas se encuentran lo suficientemente fundadas como para pasar por alto los razonamientos adoptados dentro del marco de un procedimiento judicial dirigido hacia la obtención de un resultado justo y, por lo mismo, en principio, definitivo.

\section{Principio de igualdad ante la ley}

Para algunos la igualdad ante la ley más que un derecho fundamental constituye un principio general ${ }^{3}$ que debe utilizarse para interpretar armónicamente cualquier norma del ordenamiento jurídico, de lo que se desprende que en rea-

3 Fernández (2001), p. 38. 
lidad el derecho subjetivo detrás del artículo 19 número 2 de la Constitución Política de la República corresponda al derecho a no ser discriminado por razones odiosas, injustas o irrazonables. Además, la igualdad es un concepto abierto o indeterminado que sólo adquiere sentido cuando se lo vincula con una relación concreta en que vayan a ser comparados dos o más términos y que complementa el valor de la justicia, en cuanto se debe "dar a cada uno lo suyo", como sostenía Ulpiano, pero siempre respetando las diferencias y no incurriendo en discriminaciones ${ }^{4}$.

Según Robert Alexy ${ }^{5}$, en su formulación más básica, el principio en comento importa tratar de la misma manera a quienes son iguales, y a la inversa, tratar distinto a quienes son diferentes al menos en alguna propiedad que se considera como relevante para efectos de un determinado tratamiento, utilizando un determinado criterio (razones) del cual dependerá la validez del trato diferenciado o equiparado según corresponda en el caso en particular.

En este orden de ideas y aceptando de antemano los fundamentos que se dan para validar el indulto, podemos aseverar que el indulto general respeta la igualdad ante la ley siempre que vaya dirigido a un grupo más o menos amplio de personas, sin excluir arbitrariamente del beneficio a ciertos individuos, a pesar de que desde otro punto de vista puede decirse que ambos constituyen per se excepciones al principio de igualdad, puesto que intrínsecamente conllevan un trato diferenciado para personas que se encuentran en la misma calidad de condenados que otros, incluso por el mismo delito o al menos por uno de naturaleza similar que afecte el mismo bien jurídico. Tratándose del indulto particular, comúnmente llamado "indulto caso a caso", el nexo con la igualdad se torna aún más crítico, ya que mediante esta facultad, el Presidente de la República deja en libertad a un determinado individuo vía decreto supremo, o bien reduce la pena o la conmuta por otra menos gravosa. Lo complejo de indultar de esta forma consiste en que bajo el amplio y valórico argumento de la necesidad de calmar la agitación social, se otorga un verdadero privilegio, contradiciendo de esta manera lo prescrito en nuestra Carta Magna en su artículo 19 número 2 inciso primero: "En Chile no hay persona ni grupo privilegiados", por lo que el Primer Mandatario debería otorgarlo restrictivamente sólo en casos muy calificados, al carecer estos indultos de la objetividad y generalidad indiciarias del respeto al principio de igualdad ante la ley.

${ }^{4}$ Digesto. 1, 1,10 pr.= Institutiones Iustinianis 1, 1, pr. Citado por IgLesias (2008), p. 58.

5 Alexy (2001), pp. 388-398. 
La constitucionalidad de la medida depende únicamente, a nuestro juicio, de la razonabilidad y pertinencia de los argumentos que se den para seguir manteniendo una institución que a priori pareciera carecer del sustento jurídico suficiente como para seguir aplicándose en los modernos Estados de Derecho del siglo XXI, un juicio de valor que en el caso chileno corresponde realizar preventivamente a la Contraloría General de la República a través del trámite de toma de razón y represivamente al Tribunal Constitucional cuando conozca de alguna acción de inconstitucionalidad. Como es lógico y considerando nuestra actual realidad constitucional, ambos órganos no cuentan con la potestad suficiente como para oponerse a estos indultos, ya que se encuentran con el obstáculo insalvable de la propia naturaleza de los mismos, por lo que el único camino jurídico viable al parecer sería la reforma al artículo 32 número 14 de la Constitución Política o derechamente su derogación junto a otras disposiciones dispersas por el ordenamiento jurídico, tales como los artículos 32 bis. Regla tercera y 93 número $4^{\circ}$ del Código Penal, en lo que al indulto particular se refieren.

\section{Capítulo II}

\section{ANÁLISIS DE LA DISCUSIÓN SOBRE LA PROPUESTA DE “INDULTO BICENTENARIO” \\ A LA LUZ DEL DERECHO INTERNACIONAL}

\section{Indulto Bicentenario}

Hace ya más de un año celebramos en nuestro país el Bicentenario de nuestra patria, instancia especial para reflexionar sobre el progreso económico, social y por qué no decirlo, cultural, experimentado en estos doscientos años de República independiente. Es en el marco de este recordatorio que surgieron voces planteando la posibilidad de indultar a condenados tal como se hiciera en el siglo recién pasado con ocasión del Centenario, cuestión que llamó la atención y más aún cuando algunos sostenían la posibilidad de perdonar a condenados no importando el tipo de delito cometido, dando lo mismo indultar a una persona que aplicó tortura y participó en desapariciones forzosas que indultar a una persona autora de un robo común, bajo el amparo de un posible indulto humanitario. El proyecto comenzó a gestarse en el año 2008 cuando la Capellanía de Gendarmería empezó a evaluar qué delitos y presos podrían recibir beneficios penitenciarios, desde entonces todos los sectores políticos dieron a conocer su punto de vista, siendo utilizado el proyecto como tema de campaña política en las últimas elecciones presidenciales, constituyendo el principal punto de discordia entre los diversos sectores el indultar o no a quienes cumplan condenas por delitos de lesa humanidad. 
En relación a la concesión de indultos existieron opiniones tan diversas, como aquellos a favor de la institución que se centran en las razones humanitarias a las que hizo alusión la Iglesia, mientras otros en abierta oposición, adujeron que la Iglesia no tenía ningún derecho a inmiscuirse en el orden temporal, que debía preocuparse de perseguir los delitos que eran cometidos por sus propios miembros y que muchas veces quedaban en la impunidad. En este mismo sentido, quedó en evidencia el rechazo ciudadano por opiniones de la propia ciudadanía, que se mostró contraria a un indulto a presos sin distinción de delitos ni condiciones entre civiles y uniformados.

En respuesta a las propuestas formuladas tanto por la Iglesia Católica como por las Iglesias Evangélicas, el Gobierno manifestó que si bien ambas ofrecían valiosas reflexiones sobre virtudes como la compasión, perdón y la reconciliación, un Estado de Derecho no puede aceptar de forma total las propuestas hechas por estas instituciones. Por lo anterior, el Presidente de la República descartó promover una ley de indulto general con motivo del Bicentenario, ya que beneficiar a personas privadas de libertad ignorando el imperio de los derechos humanos en materia de crímenes de lesa humanidad, transgredía los Tratados Internacionales vigentes suscritos por Chile, al pretender aplicar misericordia a quienes violaron de manera tan brutal los derechos fundamentales en nuestro país. Además, la experiencia vivida tras las concesiones de indultos generales más recientes ha producido en palabras del Primer Mandatario, "un clima de tensión y división que muchas veces reabre viejas heridas y rencores del pasado", en consecuencia, "incorporando todos los valores y considerando por sobre todo el interés superior de la patria y el bienestar de los chilenos, he llegado al convencimiento que, en los tiempos y circunstancias actuales, no es prudente ni conveniente promover el otorgamiento de un nuevo indulto de carácter general"(PIÑERA, 2010).

Sin perjuicio de lo anterior, las propuestas de las Iglesias fueron acogidas en parte a través de la facultad presidencial que otorga nuestra Carta Fundamental al Presidente para otorgar indultos particulares. Al respecto, el primer Mandatario expresó lo siguiente: "esta facultad debe ser ejercida de manera prudente y restrictiva, aplicándolo caso a caso, con criterios muy estrictos y principalmente que sean de carácter humanitarios, y siempre que ello no debilite nuestra lucha frontal y decidida contra la delincuencia y el narcotráfico ni la cultura de respeto irrestricto a los derechos humanos" (PIÑERA, 2010).

De este modo, descartada una ley de indulto general, se instaló la discusión sobre el indulto particular, como facultad presidencial, independientemente 
que se haya o no hecho uso de él, figura que precisamente es el objeto del presente trabajo.

\section{Una mirada critica desde el derecho internacional}

El desconocimiento y menosprecio de los derechos fundamentales han llevado a la comunidad internacional a crear sistemas y mecanismos que los protejan y los promocionen, así, teniendo como base el reconocimiento de la dignidad intrínseca y de los derechos iguales e inalienables de todos los miembros de la familia humana es que el 10 de diciembre de 1948, la Asamblea General de las Naciones Unidas aprobó y proclamó la Declaración Universal de Derechos Humanos, la que fortaleció el movimiento internacional de estos derechos, llevando posteriormente a la creación de tratados internacionales que se traducen en Pactos que conjuntamente con dicha declaración constituyen lo que se conoce por Carta Internacional de Derechos Humanos, por lo que existe todo un régimen de derecho tendiente a su protección, que a nivel regional se refleja en la existencia de un Sistema Interamericano de Derechos Humanos que cuenta con dos entidades para cumplir con su fin, que son la Comisión Interamericana de Derechos Humanos y la Corte Interamericana de Derechos Humanos, las que datan de épocas distintas y difieren en sus facultades y atribuciones, aun cuando tienen el mismo objetivo.

El Estado de Chile al suscribir diversos Tratados Internacionales de Derechos Humanos se encuentra obligado a respetar y cumplir con la normativa ratificada, porque así lo dispone tanto nuestra Constitución Política como los principios del derecho internacional público como el pacta sunt servanda y el principio de la buena fe, este efecto vinculante de la normativa internacional involucra no sólo al Poder Ejecutivo, sino también a los demás poderes o funciones del Estado que deben ceñirse a esta normativa en sus actuaciones.

La Convención Americana sobre Derechos Humanos, denominada Pacto de San José de Costa Rica, el Pacto internacional de Derechos Civiles y Políticos, el Convenio sobre traslado de personas condenadas, adoptado por el Consejo de Europa, en Estrasburgo, la Convención Interamericana para el cumplimiento de condenas penales en el extranjero, entre otros tratados suscritos por el Estado de Chile, se refieren de forma expresa a la aplicación del indulto, refiriéndose los dos primeros en forma expresa al perdón de la pena de muerte mientras las otras normativas tienen un marco de aplicación más amplio.

Ahora bien, dentro de este contexto, el punto de discordia en nuestro país no se fundó en aplicar o no el indulto (general o particular) sino más bien a quién se puede beneficiar con éste, dependiendo de la naturaleza y características de los 
delitos cometidos, surgiendo la gran pregunta ¿es factible jurídicamente indultar particularmente a condenados por delitos de lesa humanidad en nuestro país? Como lo hemos mencionado, la interrogante nace de la discusión que hubo en el espectro político hace poco tiempo en relación a la posibilidad de beneficiar a ex militares "por razones humanitarias".

Respondiendo de inmediato la pregunta planteada desde el punto de vista del derecho internacional, podemos afirmar que esto no es posible. Así, de acuerdo con la Convención contra la Tortura, de la cual Chile es signatario, los Estados están obligados a adoptar medidas apropiadas para prevenir que se cometan actos de tortura. Interpretando estas obligaciones, el Comité contra la Tortura ha sostenido que la sanción de personas implicadas en delitos de lesa humanidad, como los perpetrados por agentes estatales bajo la dictadura militar, es una exigencia que se impone a los Estados. Por lo mismo, el Comité ha señalado que el imponer penas menores o conceder indultos resulta incompatible con el deber que deriva de la Convención contra la Tortura en el sentido de imponer castigos adecuados. En el mismo sentido, el Comité ha celebrado las cláusulas constitucionales que imponen a los Estados Partes la obligación de investigar e imponer sanciones penales a los perpetradores de violaciones a los derechos humanos, declarando, además, que tales actos no pueden beneficiarse de la prescripción y debe excluirse cualquier medida que implique impunidad. Por otro lado, la Corte Interamericana de Derechos Humanos ha condenado a Chile señalando que "leyes de amnistía como la chilena conducen a la indefensión de las víctimas y a la perpetuación de la impunidad de los crímenes de lesa humanidad, por lo que son manifiestamente incompatibles con la letra y el espíritu de la Convención Americana sobre Derechos Humanos e indudablemente afectan derechos consagrados en ella. Ello constituye per se una violación de la Convención y genera responsabilidad internacional del Estado" (Nogueira, 2006). Asimismo, la Corte Interamericana de Derechos Humanos ha señalado que los Estados no pueden sustraerse del deber de investigar, determinar y sancionar a los responsables de los crímenes de lesa humanidad aplicando leyes de amnistía u otro tipo de normativa interna. Consecuentemente, estos crímenes son delitos por los que creemos tampoco pueden otorgarse indultos dado el espíritu que inspira esta aseveración. El Comité de Derechos Humanos, refiriéndose específicamente a Chile ha manifestado su preocupación por la vigencia, aun cuando no sea aplicado, del decreto ley de amnistía. En tal sentido, ha instado al Estado a transformar en ley la jurisprudencia de la Corte Suprema que no aplica el decreto de manera de descartar posibles interpretaciones en sentido contrario. 
En Argentina, la Corte Suprema de ese país sentó precedente en cuanto anuló el indulto otorgado al General Santiago Omar Riveros teniendo en vista la normativa internacional sobre derechos humanos, a la cual le otorgó jerarquía constitucional. Además, se establece que tratándose de delitos de lesa humanidad, no existen limitaciones a su juzgamiento en tiempo y espacio y tampoco podría concederse indultos o dictarse leyes de prescripción que impidan su juzgamiento y condena, también se establece en el fallo que no podía ser controvertido, que los hechos que se pretenden investigar en el caso encuadran en afecciones fundamentales a la persona calificables como de "lesa humanidad". ${ }^{6}$

De conformidad con lo expuesto y en respuesta a la gran pregunta planteada con anterioridad, concluimos que esta es negativa por las siguientes razones: 1) No es posible indultar a un autor de delitos de lesa humanidad por el carácter imprescriptible de tales delitos. 2) La no aplicación y cumplimiento concreto de las sanciones por la comisión de esta clase de delitos significaría impunidad y no adecuación de las sanciones. 3) Constituiría una violación per se a la normativa internacional del ramo que prohíbe la comisión de estos delitos. 4) Provocaría la indefensión de las víctimas. 5) No se garantizaría que estos actos no se vuelvan a repetir en el futuro. 6) Se trata de delitos que no pueden ser objeto de amnistía. 7) Finalmente, se transgredirían diversos derechos y principios fundamentales.

\section{CAPÍtulo III}

LA MANTENCIÓN DEL INDULTO EN NUESTRO ORDENAMIENTO JURÍDICO

\section{Generalidades}

Esta institución de antiquísima data ha sido objeto de numerosas críticas a lo largo de la historia, es así como ante los serios problemas que pueden surgir con su aplicación, tales como la vulneración de derechos fundamentales, la insegu-

6 “...En el 2006 la Cámara Nacional de Casación Penal revocó lo establecido por la Cámara Federal, sobre la base de la primacía del derecho de las víctimas y el deber del Estado de investigar crímenes de lesa humanidad, en relación a la garantía constitucional de cosa juzgada. También invocó el caso Kolk tramitado ante la Corte Europea, concluyendo que para el juzgamiento de crímenes de lesa humanidad no rigen limitaciones de espacio y tiempo, ni pueden dictarse indultos o leyes de prescripción. Citó diversos tratados sobre derechos humanos aprobados por la República Argentina tales como la Convención contra el Genocidio, la Convención Americana sobre Derechos Humanos y la Convención Interamericana contra la Tortura. Invocó el caso Barrios Altos de la Corte Interamericana y afirmó que sostener la cosa juzgada en este caso importa un 'beneficio que no es otro que la misma detracción de derechos fundamentales de otros sujetos', a saber el derecho a investigar las violaciones a atributos fundamentales de los seres humanos, determinar quiénes fueron responsables y aplicar las sanciones que correspondan..." (PAN et. al., (2008), p. 101. 
ridad jurídica y el renacimiento de antiguas disputas políticas, a priori pareciera que la mejor solución consistiría en optar derechamente por la derogación de tan problemático instituto; para ponderar esta alternativa hemos querido revisar los distintos argumentos que se han formulado tanto en favor como en contra del indulto, para en definitiva poder concluir si conviene o no su mantención en nuestro país, así como en cualquier otro Estado de Derecho.

\section{Beneficios derivados de su aplicación}

Para hablar de las ventajas que trae consigo la adopción del indulto, se hace imperativo rememorar la justificación misma de tan controvertida figura, la que ha servido para mantener su vigencia por tantos siglos, pese a las críticas que se reiteran cada vez con mayor vigor.

El constitucionalismo clásico reconoce como fundamentos de la gracia a la equidad, oportunidad y conveniencia pública, todos términos muy amplios, cuya imprecisión ha contribuido a sembrar en muchos serias dudas en relación a las ventajas reales de este instituto. En este orden de ideas, es difícil comprender la existencia del indulto en la actualidad, si no se analizan sus orígenes; es así como históricamente la gracia emanada del rey operaba dentro del marco de distintas razones que bajo ciertos criterios se consideran ventajosas para la buena marcha de la sociedad, tales como celebraciones públicas, por tradición (indultos de Semana Santa), o para excarcelar a quienes hubiesen sido condenados por delitos que con posterioridad han desaparecido de los distintos códigos penales, destacándose entre estas motivaciones las llamadas razones humanitarias?

De esta manera, resulta difícil encontrar casos en que se haya indultado por mero capricho, sin tener conexión alguna con las motivaciones recién expuestas,

\footnotetext{
${ }^{7}$ En las leyes 49, 50 y 51, TI. XVIII, Partida 3 se encuentran las razones por las que se concedían las gracias:

a) Por el bien que de ellas puede resultar al reino como cuando:

a.1 Se exime de pecho o de portazgo a los que pueblan algún lugar o hacen otra obra en beneficio público.

a.2 Se libra de tributos o se da otra indemnización a los que recibieron algún daño en sus bienes o en sus personas por causa de guerra o de tempestad.

a.3 Se perdona a algunos malhechores porque hagan un servicio de mucha importancia.

b) Por la necesidad que hay de hacerlas a fin de evitar algún mal como cuando se suelta o se perdona o se alza destierro o se permite la extracción de cosas prohibidas para alejar el peligro inminente de revueltas intestinas, de represalias o de guerra.

c) Por el mérito de los servicios que alguno hubiere contraído o estuviese en disposición de contraer en bien del Estado en razón de su valor, lealtad o saber. Escriche (1851), p. 736.
} 
las que en definitiva conllevan un beneficio tanto para el indultado como para la comunidad en general.

En la actualidad, se observa una suerte de perfeccionamiento de estas motivaciones, concibiendo al indulto como una herramienta de paz social y de compasión desde los Estados.

En nuestro país, don Juan Enrique Vargas expone sistemáticamente las argumentaciones que comúnmente se dan en defensa del indulto particular, las que a continuación pasamos a revisar:

a) Se justifica por un imperativo de justicia, con el fin de reparar posibles errores judiciales.

b) Para suavizar la aplicación de leyes demasiado severas en situaciones concretas que no pudo predecir el legislador. La justicia estructural no siempre expresa la justicia como valor humano y divino, así, el indulto se convierte en un acto de administración de justicia vedado a los jueces y una necesidad de la compensación de los límites que tienen éstos en la función aplicativa del Derecho ${ }^{8}$.

c) Para lograr la paz social y la tranquilidad pública?.

d) Para obtener la enmienda del condenado que ha mostrado tener buena conducta.

e) Por último, se fundamenta en que con él puede atenuarse la aplicación de la pena de muerte y hacer al mismo tiempo el experimento de su supresión de hecho antes de llegar a la abolición legal.

Tras esta exposición, Vargas critica cada uno de estos argumentos, concluyendo que existen otros mecanismos jurídicos que pueden cumplir con estos fines, tales como la derogación o modificación de normas, o la ampliación del ámbito de aplicabilidad de los distintos recursos judiciales existentes en la actualidad.

En cuanto a los derechos fundamentales se refiere, al tratar el tema señalamos lo beneficioso que puede resultar esta medida para el indultado, desde el punto de vista de sus derechos a la libertad, a la dignidad y respeto de la persona humana e incluso a la vida e integridad física y sicológica, cuando se conceda a condenados que sufren de enfermedades terminales o graves o a quienes la naturaleza de las condiciones carcelarias puede colocar en grave riesgo su vida, salud e integridad.

${ }^{8}$ Así también lo expresaba Ihering, al considerar que el derecho de gracia podía ser una válvula de seguridad del derecho, corrección de la generalidad del ius strictum frente a las exigencias de la equidad, alegando que se presentan a veces ciertas circunstancias en las cuales es más útil perdonar que castigar, más acertado olvidar que perseguir o, simplemente, templar las asperezas de la ley. (De CARRERAS, 2000).

${ }^{9}$ Etcheberry (1997), p. 251. 
En lo que respecta al derecho fundamental a la vida, numerosos tratados internacionales contemplan expresamente al indulto y a la amnistía como mecanismos de protección de la misma frente a la pena de muerte, entre los que destacan la Convención Americana sobre Derechos Humanos, conocida como Pacto de San José de Costa Rica (artículo 4º), y el Pacto Internacional de Derechos Civiles y Políticos (artículo $6^{\circ} \mathrm{N}^{\circ} 4^{\circ}$ ), con lo que queda ratificada la importancia que se le atribuye en Derecho Internacional a esta facultad.

De esta forma, el indulto particular siempre aparecerá como beneficioso en relación a la tutela de los derechos recién expuestos, mientras que desde otra perspectiva, siempre afectará potencial o efectivamente otras garantías constitucionales y/o bienes jurídicos de las víctimas agredidas por el indultado, o bien, de los familiares de éstas, los cuales se tratarán más adelante.

El autor peruano Walter Robles, considera como otras justificaciones del indulto, la existencia de casos en que se considere que no están bien probados los hechos materia de la condena o que no existe causa probable para procesar, y el principio penal de que lo que se consideró justo en un instante deviene injusto posteriormente por el cambio de las circunstancias, o de la personalidad del inculpado, lo que se conoce como rebus sic estantibus. ${ }^{10}$

La doctrina española, por su parte, ha desarrollado la vinculación existente entre la figura del indulto del Monarca con la justicia material como fin del Derecho concibiéndolo como una herramienta para alcanzarla, al punto de que según algunos éste sería "un acto de justicia contra la justicia"(CARRASCO, 1998, p. 145), ya que en casos concretos puede subsanar situaciones de injusticia que innegablemente se presentan y que dicen relación con el carácter de firmes y ejecutoriadas de las resoluciones judiciales que impide discutirlas.

Se ha dicho, también, que en política criminal el indulto particular nunca dejará de tener justificación, particularmente, en presencia de una condenación firme de largo plazo y a favor de quienes estén incapacitados para cumplirla o frente a quienes el cumplimiento de la sanción de encarcelación no aportará ninguna ventaja. En España, por ejemplo, han sido memorables los casos en los cuales los tribunales pronuncian sentencias de condenación y al mismo tiempo solicitan el indulto; por ejemplo, en una sentencia del Tribunal Supremo de 28 de febrero de 1992, a Enrique Ruiz Vadillo, el tribunal le confirmó la sentencia impuesta en estricta aplicación de la ley y a la vez le solicitó el indulto por razones de equidad y de justicia, particularmente, porque al haber transcurrido cerca de 14

10 Robles (2010). 
años de la comisión de los hechos, se estaba juzgando un hombre distinto en sus circunstancias personales y sociales, por lo que la pena no cumpliría su función de ejemplaridad, rehabilitación o de reinserción social ${ }^{11}$.

Por otro lado, al igual que la amnistía, el indulto particular puede contribuir en determinadas situaciones a la pacificación social en relación con profundos conflictos que se dirimen en el seno de una sociedad. A pesar de que existen críticas a esta fundamentación, en relación a que pareciera más adecuado indultar de forma general en estos casos, en razón de que una agitación política sólo podría ser provocada por un gran número de involucrados, no estamos de acuerdo con esta postura, por lo que nos parece que un indulto particular puede aplicarse perfectamente respecto de autores individuales de delitos políticos ${ }^{12}$.

\section{Criticas}

Luego de haber analizado los beneficios que trae aparejada la figura en estudio pasaremos a desarrollar los perjuicios que, a nuestro parecer, acarrea la permanencia de ésta.

Como se sabe el indulto particular es un resabio absolutista de las monarquías europeas, propenso a los abusos de poder, todo lo que es contrario a los principios imperantes en un Estado de Derecho, en donde los ámbitos de atribución de cada poder del Estado están claramente definidos, lo que dista de aquellos años en los cuales las funciones se confundían en la persona del monarca. En consecuencia, en relación a la evolución que ha manifestado el Derecho y a su adecuación a las características de la sociedad, es que una institución como ésta, concebida en su forma original, no se justifica en la actualidad.

11 GERMÁn (2008).

${ }^{12}$ Refiriéndose a este beneficio social que trae aparejada toda forma de gracia, el jurista alemán Carl Schmitt señalaba: "las amnistías, como los indultos, no se miden con la vara de lo justo o las tablas de lo verdadero ni caben dentro de la esfera religiosa del perdón. Resultan, en cambio, una forma excepcional de ejercicio de la razón de Estado, con el solo objetivo de obtener aceleradamente la concordia luego de una gran tribulación política. Amnistías e indultos, por cierto, no son un bálsamo, sino más bien un zurcido, y necesariamente dejan una secuela de injusticias y dramas irresueltos. Pero téngase en cuenta que la contrapartida de amnistías e indultos, puede ser, y casi siempre es, no sólo la perpetuación de la lucha faccionaria y el anclaje de la sociedad en ese episodio de su pasado, sino la afirmación de que toda guerra civil debe tener necesariamente un ganador absoluto, que debe seguir librándose hasta que tal circunstancia resulte evidente, y que el perdedor carece no sólo de todo derecho o justificación, sino que directamente es depuesto de su condición humana y convertido en un alienígeno despreciable". BANDIERI (2007), p. 6. 
Por otro lado, si bien el indulto es una figura jurídica, es innegable que en las decisiones tomadas por el Primer Mandatario pudiese verse reflejado un carácter político, tintes de moralidad e incluso razones económicas dada la amplia discrecionalidad que se le otorga, por lo que se podría incurrir en arbitrariedades al no contemplar nuestra legislación los supuestos específicos en base a los cuales se puede otorgar un indulto particular.

La Ley No 18.050 de 1981, que fija las normas generales para conceder indultos particulares, establece las circunstancias en que debe encontrarse aquella persona que solicite este beneficio y las características que debe contener la solicitud; sin embargo, considerando que los motivos de la concesión deben ser restrictivos, no existen en Chile cuerpos legales que ilustren de forma explícita las razones por las que se podría otorgar este beneficio, lo que parece necesario para ejercer una tutela efectiva de los derechos fundamentales.

Por otra parte, la gracia provoca en muchos casos el repudio social, en especial, cuando recae sobre delitos que han sido de gran impacto colectivo. No es novedoso afirmar que Chile es un país de cultura inquisidora y profundamente vengativa, así, la gracia provoca un sentimiento de impotencia en la población, lo que atenta en contra del destino final del Derecho, como lo es la convivencia armónica de la sociedad.

\section{Su mal uso a través de la historia}

El hecho de que esta facultad pueda ser utilizada por el Presidente de manera libre y al no existir en la ley ni en el reglamento que la regulan un listado de motivaciones para su otorgamiento, trae aparejado dos grandes vicios que son la arbitrariedad al poder indultarse sólo por mera voluntad y una disparidad de criterio, puesto que la persona del Presidente de la República va cambiando con los años, así como varían las tendencias políticas. Por lo anterior, ambos vicios han llevado a un mal uso de la facultad a través de la historia ${ }^{13}$.

\footnotetext{
${ }^{13}$ A modo de ejemplo pueden mencionarse los polémicos indultos del ex Presidente de Estados Unidos, Bill Clinton, quien en el último día de su mandato indultó al millonario Marc Rich, fugitivo en Suiza desde 1983, incriminado por evasión de impuestos, fraude y comercio petrolero ilegal en Irán. Hubo un escándalo mayúsculo porque la ex cónyuge de Rich, Denisse, fue una importante contribuyente del Partido Demócrata, y en la campaña de Hilary Clinton para Senadora. También donó alrededor de 450 mil dólares al Fondo de Biblioteca Presidencial de Clinton. Incluso, el cuñado del ex Presidente, Rodham, se vio obligado a devolver cerca de 250 mil dólares a cambio del perdón presidencial para Rich. Los Clinton, afirmaron que desconocían esos arreglos y conminaron a su pariente a devolver el dinero. La Fiscal Mary Jo White, inició
} 


\section{Afectación de labores gubernamentales}

Podemos observar que tanto el uso y los deseos de recurrir a esta facultad han ido disminuyendo con los años en nuestros mandatarios y aspirantes al sillón presidencial, prometiendo incluso en sus programas de gobierno no utilizarla, lo que denota que sus preocupaciones y políticas públicas están enfocadas hacia otros horizontes y que una institución como el indulto interfiere y afecta los cometidos específicos de gobierno, dejando a quienes pueden indultar en un difícil dilema en relación a las repercusiones sociales que lleva consigo el tomar una u otra vía.

\section{Instrumento populista}

El indulto presidencial puede llegar a ser mal utilizado tan sólo con el fin de ganar la simpatía de la población aludiendo a razones humanitarias y de clemencia que tanto gustan a la audiencia, dejando de ser una herramienta jurídica "útil", para convertirse en un mero instrumento populista que no consideraría las verdaderas justificaciones a que se apunta a la hora de excusar la permanencia de la institución.

\section{Intervención en el Poder Judicial}

Se ha justificado el uso de la facultad en estudio como remedio a la aplicación de la ley de un modo mecánico que pudiese llevar a absurdos que merecen ser corregidos por un poder distinto de aquel que la aplicó, como contrapartida podemos decir que en la actualidad la labor judicial es más bien una labor intelectiva, en que el juez puede, con márgenes de libertad y mediante interpretaciones, aplicar la ley en uno u otro sentido según se presente el caso concreto. En este contexto, el indulto emanado de una autoridad ajena al Poder Judicial quien es el órgano encargado de administrar justicia, carece de todo sentido, pues nuestra legislación cuenta con dispositivos que permiten aplicar la ley de un modo que no se produzcan absurdos ${ }^{14}$. De ahí que la permanencia del indulto conlleva a

una investigación sobre la gracia presidencial para ver si Clinton había violado la ley al conceder el indulto, pero ésta quedó firme e incólume. Robles (2010), p. 7.

${ }_{14}$ Proyecto de Ley No 5.945 "Deroga facultades presidenciales para otorgar indultos particulares". Boletín No 5561-07. En: http://camara.cl/pley/pley_detalle.aspx?prmID=5945\&prmBL=5561-07 (visitado el 27/09/2012). 
ultrajar la independencia del Poder Judicial, dando una mayor ponderación al interés de una persona por sobre el bienestar del Estado.

\section{Promueve la impunidad}

En el entendido que es el Estado el titular del ius puniendi, poderosa instancia pública capaz de resolver el conflicto criminal de forma pacífica e institucional, racional y previsible, con respeto de las garantías individuales, sólo esta facultad estatal se encuentra en condiciones de asegurar la justa tutela de los bienes jurídicos fundamentales y siendo los tribunales competentes para dirimir controversias, los encargados de aplicar las leyes e imponer las penas, su contrario sería la impunidad, a lo que se llegaría con la utilización del indulto, pues si bien en un principio se sanciona, posteriormente se conmuta o se remite la pena, lo que viene a socavar el espíritu de disputa contra la impunidad, yendo a contracorriente de la tendencia mundial de lucha contra la misma.

\section{Su ejercicio por quien no tiene la potestad}

El Decreto No 924 de 1981 permite que la resolución que otorga un indulto sólo sea firmada por el Ministro de Justicia y no por el Presidente, actuando por "orden" de éste. La práctica ha demostrado que la interpretación que se le estaría dando a esta disposición es errónea, por cuanto delegación de firma jamás constituye delegación de la atribución presidencial.

Otorgar los indultos por una autoridad que no tiene la potestad para hacerlo, significa una grave contravención a lo estipulado por nuestra Carta Fundamental, por lo que podemos señalar que la aplicación de esta figura no está cumpliendo con los conductos legales, generando serias contravenciones que un Estado de Derecho no puede permitir.

\section{Inseguridad jurídica}

La gracia afecta la aplicación de las penas por cuanto éstas se ven interrumpidas, contraviniendo la firmeza de las sentencias judiciales; en consecuencia, la seguridad jurídica entendida como la certeza respecto de cómo ocurrirán las cosas reguladas por el Derecho, se ve manifiestamente vulnerada por dicha figura. Aun cuando las razones para indultar consisten principalmente en criterios humanitarios, éstos muchas veces no tienen el peso suficiente para pasar por alto las decisiones adoptadas por los tribunales de justicia, por lo que dichas penas deben ser cumplidas sin excepción. 


\section{Derechos fundamentales}

En caso de no entregarse por parte del Presidente de la República argumentos razonables y suficientes para su concesión a un determinado individuo en desmedro de otros que se encuentran en similares condiciones; indudablemente, tendría lugar una contravención al principio de igualdad ante la ley.

Como dijimos en su oportunidad el indulto general normalmente no contraviene este principio, pero tratándose del indulto particular por su propia naturaleza, deberá siempre cuidarse de justificar debidamente el trato diferenciado.

Además, de indultarse a autores de delitos de gran lesividad, como los crímenes de lesa humanidad, es indudable que se afectaría de forma incalculable el derecho a la honra de la persona y de su familia y la dignidad de los familiares de las víctimas de derechos humanos.

Por último, al hacer el Presidente uso de esta facultad constitucional inevitablemente actúa de manera indirecta en contra del debido proceso, pues altera lo establecido por sentencia ejecutoriada en procesos que se llevaron a cabo con pleno respeto a las garantías de las partes involucradas en los mismos.

\section{Nuestra opinión}

Al ponderar los argumentos expuestos, nos encontramos con que las motivaciones del indulto (equidad, oportunidad y conveniencia pública) también sirven de sustento a muchas instituciones jurídicas actualmente vigentes, las que no han sido objeto de cuestionamientos tan severos como lo ha sido éste. Por lo demás, los Estados son entes colectivos conformados por una diversidad amplia de instituciones que se complementan entre sí, siendo aconsejable optar por una relación estrecha entre los poderes estatales.

A pesar de la existencia de estas críticas estamos por aceptar el indulto por razones humanitarias, pues desde nuestro punto de vista, de ser efectivas estas motivaciones se estarán beneficiando derechos fundamentales sin vulnerar la igualdad ante ley. En consecuencia, bajo el entendido de que el indulto denota rasgos positivos de piedad y perdón coherentes con el pensamiento actual sobre el Derecho Penal, encapsulados en una regulación antigua, y estando superado el pensamiento que postula la pena como castigo, no podemos adoptar otra postura que no sea tomar parte de quienes piensan que el Estado debe intervenir en el conflicto penal, velando por el resguardo de aquellos derechos fundamentales de mayor preponderancia en un caso concreto. 
Por lo anterior, creemos necesario reformar esta figura para poder terminar con los abusos potenciales de los que ha sido precursor; derogarla, en cambio, constituiría una pérdida grave dentro del ordenamiento jurídico siendo muy difícil de reemplazar por otra de similares características.

\section{Capítulo IV}

\section{Propuestas EN TORNO AL INDULTO PRESIDENCIAL}

\section{Justificación del control del indulto}

El control del indulto ha constituido un escenario de discusiones muy interesantes a nivel nacional e internacional. La constante evolución del Estado de Derecho es razón suficiente para iniciar la tarea de reforma de institutos jurídicos como éste y para idear mecanismos para que su ejercicio se ajuste a un sistema jurídico muchas veces más moderno y proteccionista.

No debe olvidarse que la soberanía reside en la nación, esto es, en los nacionales de un determinado país, quienes entregan su ejercicio a las autoridades que establece la Constitución. Así, las leyes y particularmente el indulto son una manifestación de ese ejercicio debiendo, en consecuencia, respetar los límites que emanan de quienes verdaderamente entregan ese poder. Esos límites están señalados en el artículo $5^{\circ}$ de nuestra Carta Fundamental al prescribir que "es deber de los órganos del Estado respetar y promover tales derechos (derechos esenciales que emanan de la naturaleza humana) garantizados por esta Constitución y por los Tratados Internacionales ratificados por Chile y que se encuentren vigentes". En este orden de ideas, es necesario recordar que el indulto, al constituir un acto de gobierno que se realiza en ejecución de un mandato constitucional, debe conformarse a la normativa de la Carta Fundamental, lo que consecuentemente se traduce en la sumisión irrestricta a los derechos fundamentales contenidos en ella.

La doctrina hispana ha apoyado esta idea, así para García San Martín la motivación o ultima ratio por la cual el Gobierno decide conceder o denegar el indulto ha de estar debidamente conformada no sólo a los principios que inspiran y justifican la institución, sino a la Constitución y al resto del ordenamiento jurídico; esto, porque el indulto es una institución eminentemente constitucional y su ejercicio supone tanto una excepción al principio de separación de poderes como al ius puniendi del Estado, excepciones que necesariamente han de estar avaladas en un Estado Constitucional de Derecho, por razones o motivaciones igualmente excepcionales, que no son susceptibles de ser improvisadas o determinadas de forma espontánea por el concedente, sino que han de estar ciertamente 
delimitadas y acotadas, siendo así del todo necesario y exigible el control que se enuncia como aquel que tiene por objeto la garantía de la correlación o adecuación de la razón de que se sirve el Gobierno para otorgar o denegar el indulto con las razones que legitiman su ejercicio ${ }^{15}$.

La armonía que con el sistema jurídico debe tener el indulto pretendemos asegurarla mediante la incorporación de un control. Nuestra propuesta pasa por que dicha intervención no se circunscriba sólo al aspecto jurídico, sino que, además, pretendemos implementar un control de tipo político. La significación de este último, según César Aguado Renedo, "deviene de su propio carácter: frente al del control jurídico, que es objetivo, el carácter del control político es 'subjetivo', de manera que el parámetro a utilizar en él es 'no objetivado', disponible y no necesariamente preexistente, es decir, tal parámetro consiste en 'juicios de valor"' (GARCíA, 2007, p. 266).

Lo expuesto brinda una mayor flexibilidad al momento de ejercer un control sobre esta figura, pues si creemos que ésta puede otorgarse por motivos ajenos al Derecho, es menester regular que tales motivos no sean arbitrarios ni que vulneren derechos fundamentales, abriendo de esta manera la posibilidad de criticarla políticamente, situación que se daría perfectamente en caso de que se haya aplicado en un momento inoportuno.

\section{Diversidad de propuestas}

Numerosas han sido las propuestas que se han hecho en relación a esta institución, las que van desde la derogación total hasta la realización de sutiles modificaciones, pero lo que sí está claro es la necesidad imperiosa de innovar en la materia, en atención al carácter obsoleto de sus disposiciones.

Lamentablemente, la labor de reforma es un tema sumamente complejo que requiere de voluntad política y medios económicos para su ejecución, erigiéndose como una tarea pendiente para Chile en orden a trasparentar el medio de perdón penal por excelencia, siendo una actividad inexcusable que debemos enfrentar con celo y espíritu crítico.

Comenzaremos dando algunas alternativas respecto de las modificaciones a esta institución que han sido propuestas por la doctrina en el último tiempo.

La alternativa más radical consiste en derogar este instituto, esta propuesta tiene sus fundamentos en el decaimiento que ha tenido la utilización de la pena

15 García (2007), p. 277. 
de muerte en muchos ordenamientos jurídicos, lo que deja a la institución carente de su fundamento original en torno a contrarrestar la aplicación de la pena capital. Además, estamos contestes en el hecho que de existir métodos de rehabilitación y reinserción de las personas privadas de libertad junto a políticas carcelarias que aseguren la indemnidad de la dignidad humana, no se justificaría en lo más mínimo la existencia de este instituto de ultima ratio, así, el día que esto se cumpla a cabalidad no existirá la necesidad de contar con figuras de "salvataje", pero hasta ese momento no abandonaremos la discusión.

Se ha presentado, también, la necesidad de conferir al indulto la calidad de facultad efectivamente presidencial. Aunque parece extraño, una institución que tradicionalmente ha correspondido al Presidente, ahora se sitúa en manos de los Ministros, que en su calidad de colaboradores directos de éste, han participado del proceso aún más activamente que el mismo Jefe de Gobierno. Creemos que esta solución es coherente con los fundamentos mismos de la institución, al ser un asunto tan delicado y trascendente para el futuro del condenado, pero no es del todo satisfactoria, ya que no subsana la mayoría de los perjuicios generados con la aplicación del indulto.

Finalmente, se han dado soluciones que apuntan a modificar la institución, las medidas tienen por finalidad transparentar el proceso y acotar las causas del indulto, generalmente, limitándolas a razones humanitarias. A opinión nuestra, estas reformas van en dirección, en su mayoría, a evitar arbitrariedades y vulneración de derechos fundamentales, no obstante no estamos de acuerdo en limitar el indulto sólo por razones humanitarias, esto por la necesidad constante de contar con instituciones que estabilicen el escenario en tiempos de exaltación social, generalmente, cuando se quiebra la institucionalidad de un Estado.

\section{Nuestra propuesta}

En atención a las ventajas y desventajas presentadas anteriormente, expondremos la vía que, a nuestro juicio, mejor responde a la necesidad de contar con una institución moderna que concilie armoniosamente una facultad discrecional con el control de la arbitrariedad.

\section{Iniciativa}

El indulto es una institución de iniciativa exclusiva del Presidente de la República, no pudiéndose hacer reemplazar por persona alguna. Sin perjuicio de lo anterior, está permitido el asesoramiento al Presidente por parte de Ministros u 
otras personas e instituciones para tomar decisiones con la debida información sobre el beneficiado y las circunstancias que motivan el acto. Estos actores se encuentran vedados de resolver acerca de la concesión del indulto, quedando su labor limitada expresamente a tareas de apoyo y consulta.

Hemos querido conservar el carácter exclusivo del instituto, pero lo hemos limitado sólo a la iniciativa, para con ello evitar arbitrariedades y vulneración de derechos fundamentales. También hemos querido restringir la participación directa de los Ministros de Estado, situación que se presenta hoy y que ciertamente ha desembocado en indultos desinformados y de muy poca conveniencia social.

En consecuencia, el indulto presidencial debe quedar en manos del Primer Mandatario, quien posee la potestad exclusiva de otorgar un perdón cuando por circunstancias extraordinarias debe hacerse una excepción en el cumplimiento efectivo de una condena. El acto debe ser firmado por él y por el Ministro respectivo, debiendo contener los fundamentos que motivaron la decisión, así como la exposición clara y sistemática del acto ilícito cometido, la conducta del condenado, tanto de antes como durante el cumplimiento de la sentencia y, cuando corresponda, el período que efectivamente ha estado privado de libertad.

Es en este momento donde se evitan indultos arbitrarios. Si bien la iniciativa es discrecional, no por ello debe dejar de expresarse los motivos tenidos en vista al momento de conceder la gracia. El Presidente es libre para concederla a la persona que considere adecuada y por los motivos que estime convenientes, pero una vez decidido, éste debe expresar cuáles fueron tales motivaciones.

El Tribunal Constitucional español en este mismo sentido ha señalado que "la regla general de la igualdad ante la ley contenida en el artículo 14 de la Constitución, es asimismo igualdad en la aplicación de la ley, lo que impone que un mismo órgano no puede modificar arbitrariamente el sentido de sus decisiones en casos sustancialmente iguales y que cuando el órgano en cuestión considere que debe apartarse de sus precedentes tiene que ofrecer para ello una fundamentación suficiente y razonable”. (GARCÍA, 2007, p. 281). Si bien la disposición corresponde al ordenamiento jurídico español, el razonamiento es plenamente aplicable al Derecho chileno y específicamente a la facultad discrecional del indulto, constituyendo una interpretación razonable que va en la línea de lo propuesto precedentemente. Se protege, además, la identidad del beneficiado y la información que le pueda causar algún perjuicio, protegiendo así el llamado "derecho a ser olvidado".

Asimismo, el Presidente deberá cuidar siempre de no exponer indebidamente los antecedentes de la propuesta que puedan afectar la dignidad u honra del 
beneficiado. La misma obligación le corresponderá a todos aquellos órganos que intervengan en la tramitación del indulto, quedando prohibido ventilar información que pueda poner en riesgo el proceso.

\section{Control Político}

Proponemos incluir como la primera de dos instancias un control que revista caracteres de político con el objetivo fundamental de determinar si el indulto es políticamente correcto, o bien, que éste no sea inoportuno o inconveniente; asimismo, evitar las discusiones y desequilibrios observados en torno al Indulto Bicentenario, al que hicimos referencia anteriormente. No es menos cierto que con añadir este tipo de control también pretendemos se alcance una mayor integración de las funciones del Estado.

Esta instancia quedaría radicada en el Senado, órgano caracterizado por su tendencia reflexiva quien conocerá del asunto a través de una de sus comisiones permanentes, ya sea subsumiendo dicha labor dentro de las ya existentes o bien en una nueva creada para tal efecto. Las facultades de esta Comisión, en cuanto a la materia sujeta a revisión, se limitarán a lo estrictamente político quedando vedada la posibilidad de revisión de aspectos jurídicos, cuyo análisis se entregará a un control posterior de juridicidad; de lo contrario, la segunda instancia que proponemos carecería de toda utilidad.

Creemos innecesario referirnos detalladamente a aspectos orgánicos y de funcionamiento de esta Comisión, por escapar al objeto de nuestro trabajo.

Una vez firmado el indulto por el Presidente de la República será enviado a esta Comisión, el que será notificado al Presidente de la misma para que cite a una primera sesión, dando paso de inmediato a la Etapa de Indagación de Antecedentes. En esta etapa la Comisión tendrá la facultad de solicitar informes a instituciones públicas y/o privadas cuando lo estime conveniente, sin perjuicio del derecho contemplado en el artículo 19 No 14 de la Constitución Política de la República. Estas opiniones no serán vinculantes para la Comisión, adquiriendo un carácter meramente consultivo e informativo. En cuanto al contenido de estos informes, sólo se considerarán aquellos aspectos que no guarden relación con lo estrictamente jurídico.

A nuestro juicio, todo lo expuesto hasta aquí es de mucha conveniencia, puesto que se mantiene la discrecionalidad del indulto, evitando de paso arbitrariedades, existiendo una diversidad de criterios de control, tanto políticos como judiciales.

La Comisión dispondrá de un plazo de quince días hábiles para recabar la información necesaria en miras a determinar la efectividad de los antecedentes contenidos en la iniciativa de indulto, plazo que será improrrogable. 
El indulto podrá ser rechazado por la Comisión, especialmente si ésta determina que los antecedentes que sirven de base e influyen sustancialmente para su concesión son falsos. Hemos querido con esto evitar experiencias poco felices ocurridas en países vecinos ${ }^{16}$.

Una vez extinguido el plazo destinado a recabar antecedentes, la Comisión conocerá del asunto en sesiones fijadas por el presidente de la misma, pudiendo realizarse tantas sesiones como se estimen necesarias para la mejor resolución del asunto, las que deben celebrarse dentro del plazo con el que cuenta la Comisión para resolver la propuesta de indulto que se señalará a continuación.

\section{Resolución de la Comisión}

La Comisión deberá pronunciarse en el plazo improrrogable de diez días hábiles contados desde el término del plazo de investigación.

Creemos necesario instaurar un alto quórum para la aprobación del indulto, que inste a buscar consensos políticos, lo que se explica por la complejidad de los asuntos a ser resueltos y por el carácter excepcional que queremos imprimir en la institución. Proponemos que la Comisión acepte el indulto sólo cuando cuente con el voto favorable de a lo menos dos tercios de sus miembros en ejercicio, no debiendo fundamentarse la decisión, la que tendrá el carácter de definitiva.

En cuanto al rechazo de la propuesta de gracia; en general, éste se producirá cuando comprometa gravemente la paz social, de modo que su aceptación provoque un clima de repudio e impotencia social, todo lo cual quedará a criterio de la Comisión, la que además podrá desechar de plano un indulto sujeto a control cuando estime que con él se ha querido insistir de forma encubierta con uno rechazado con anterioridad, que verse sobre la misma persona y los mismos hechos. En caso de que la Comisión haga uso de esta facultad respecto de un indulto que incluye a más de una persona, éste se entenderá rechazado sólo para ella, siguiendo la tramitación normal respecto de las demás.

De no aprobarse la propuesta, no se concederá el indulto, sin ulterior recurso.

${ }^{16}$ Refiriéndose a la nulidad del indulto otorgado al empresario José Enrique Crousillat en Perú, el abogado constitucionalista César Valega afirma que a través de la historia, desde la cultura griega, esta potestad de conceder el indulto es del jefe del Estado sólo cuando él está convencido. Es decir, no hay ninguna razón que fuerce al presidente a otorgarlo. De tal manera, que si las razones que él creyó que se daban en la realidad, y ha sido engañado, el Presidente puede indudablemente revocar el indulto. (RPP NOTICIAS, 2010). 
Con estas modificaciones hemos querido dar libertad para rechazar el indulto por motivos extensos, que no sólo comprendan cuestiones jurídicas, sino además se eviten otras consecuencias perniciosas para la población, todo lo cual ayuda de buena manera a preservar la paz social y la seguridad jurídica.

La resolución que rechace el indulto deberá notificarse al Presidente de la República dentro de los cinco días siguientes, mientras que la resolución que lo apruebe deberá ser notificada tanto a éste como al Tribunal Constitucional, dentro del mismo plazo.

En síntesis, hemos optado por dotar a la Comisión de facultades investigadoras que le permitan tomar conocimiento acabado de los antecedentes y motivaciones del asunto, en especial, de su efectividad. El plazo para pronunciarse no será prorrogable en el entendido que en esta etapa se debe disponer de todo lo necesario para la discusión, además se cuida de no extender el proceso más allá de lo necesario, lo que puede ser perjudicial para él mismo, el beneficiario y para las labores de los miembros de la Comisión.

Respecto de la improcedencia de recursos y acciones en contra de la resolución de la Comisión, se ha tomado esta decisión para evitar la inseguridad jurídica que ha sido acusada por un sector importante de la doctrina.

\section{Segunda instancia de control}

No basta sólo con incluir una revisión de carácter político, creemos también imperiosa la existencia de un examen de juridicidad llevado a cabo por el Tribunal Constitucional, órgano que por antonomasia ejerce el control constitucionalidad en nuestro país.

Dentro de las funciones contempladas en nuestra Constitución no se encuentra, como es lógico, la de controlar la juridicidad de la propuesta de indulto, por lo que creemos que sería necesario introducir una modificación constitucional que apunte precisamente a establecer la función mencionada.

Sin perjuicio de lo anterior, creemos que dentro de nuestro ordenamiento jurídico no existe ningún órgano de mayor idoneidad para realizar esta función, puesto que el Tribunal Constitucional cuenta con una vasta experiencia en materia de Derechos Fundamentales, barrera esencial que debe superar el indulto para que opere y produzca los efectos que le son propios.

El objetivo principal de esta etapa es ejercer un control de constitucionalidad del indulto, de modo de impedir categóricamente cualquier vulneración de Derechos Fundamentales, así como de las normas de Derecho Internacional 
imperativas e inderogables y evitar especialmente que se beneficie a los condenados por delitos de lesa humanidad, crímenes de guerra, contra la paz o de naturaleza genocida.

Si el indulto posee alguna de las características recién mencionadas, el Tribunal Constitucional deberá rechazar la propuesta respecto de las personas o hechos atentatorios, pudiendo excluir de la resolución desfavorable a aquellos que no califiquen dentro de los supuestos mencionados.

En cuanto al procedimiento, éste se iniciará una vez que la resolución aprobatoria de la Comisión del Senado haya sido notificada al Tribunal Constitucional y éste tenga en su poder los antecedentes necesarios. Una vez verificado esto, se dará inicio a una etapa de indagación, en la que el Tribunal, a fin de ilustrar su decisión, podrá solicitar informes a personas o instituciones públicas y/o privadas sobre aspectos jurídicos internos o internacionales, sin perjuicio de lo dispuesto en el artículo 19 No 14 de la Constitución Política.

Los informes deberán referirse a aspectos estrictamente jurídicos, no serán vinculantes para el tribunal, pero éste deberá pronunciarse fundadamente respecto de todos, incluso sobre aquellos que rechaza. Sin perjuicio de ello, creemos necesario facultar al Tribunal para que pueda excluir aquellos informes que se refieran en su totalidad a aspectos ajenos al derecho o sean reiteración de otros ya presentados.

En cuanto a su presentación, ésta podrá realizarse durante toda la etapa de indagación, la cual será de carácter meramente informativo y se prolongará por un plazo de veinte días hábiles. Este término, que por cierto es más amplio que en el control anterior, se explica perfectamente por la complejidad de las materias de que se tratan.

Si solicitado algún informe no fuere presentado dentro de término establecido para la etapa de indagación y siendo éste necesario para la correcta resolución del indulto, podrá prorrogarse el plazo de indagación por diez días hábiles, por una sola vez y por resolución fundada. Transcurrido ese plazo no podrá admitirse informe alguno.

Una vez extinguido el pazo establecido para la etapa de indagación, el Tribunal contará con un plazo de quince días hábiles, los cuales serán improrrogables. El tribunal conocerá del asunto en sala.

Creemos del todo necesario establecer un plazo más extenso del establecido para el control político, esto se debe a que el análisis que debe hacer el Tribunal Constitucional de los antecedentes es mucho más detallado y riguroso, y la resolución, tanto si aprueba o rechaza el indulto, debe ser mejor fundamentada y comprensiva de todos los informes presentados. 


\section{Resolución del tribunal}

El tribunal examinará si la propuesta de indulto es vulneradora de Derechos Fundamentales, atenta contra el Ius Cogens, recae sobre condenados de crímenes de lesa humanidad, crímenes de guerra o contra la paz o de naturaleza genocida, o pugna contra el sistema jurídico en general.

De determinarse lo anterior el tribunal rechazará la propuesta y en consecuencia se denegará el indulto, debiendo notificarse dentro del plazo de cinco días hábiles al condenado, al centro penitenciario y al Presidente de la República.

Si por el contrario se determina que no existe razón jurídica alguna para denegar el indulto, el Tribunal dictará la resolución que lo apruebe, notificándose al Presidente de la República, al centro penitenciario y al condenado dentro del plazo de cinco días hábiles.

El indulto no producirá efecto alguno sino una vez notificado conforme a la ley.

En ambos casos el Tribunal debe resolver fundadamente, pronunciándose sobre cada uno de los informes presentados, quedando vedado el Tribunal de pronunciarse sobre aspectos ajenos al derecho. Esto es lógicamente imperativo, ya que la propuesta de indulto ya fue sometida a un control anterior comprensivo de aspectos políticos y sociales. De aceptar un examen más amplio por parte del Tribunal Constitucional, implícitamente estaríamos restando eficacia al control senatorial y al mismo tiempo se estaría estableciendo un examen reiterativo, lo que pugna contra los principios de la lógica y celeridad que en todo momento deben informar este procedimiento.

Creemos que el quórum necesario para aprobar o rechazar el indulto debe ser de dos tercios de los miembros de la sala, tal y como en el caso de la Comisión Senatorial, puesto que se busca limitar el indulto a los casos en lo que no exista duda sobre su inexistente vulneración de derechos fundamentales. Sin perjuicio de ello, creemos que un quórum de mayoría simple puede también ser aceptable si se considera que ello constituye la regla general y como tal, muchas materias, también complejas, son acordadas por el Tribunal sólo por mayoría simple. Es por ello que la decisión de exigir un quórum bajo o alto es una determinación que se debe tomar en vista a los factores que hemos señalado, adoptando uno u otro según se crea cual es más relevante.

Conforme a lo propuesto precedentemente, es de toda evidencia que el indulto pasará a ser una institución profundamente reglamentada y con un procedimiento extenso y con formalidades. Podría pensarse perfectamente que esta propuesta al 
agregar controles de diversos tipos y al establecer reglas de procedimiento estrictas, sepultaría de una vez por todas y de manera casi definitiva la institución, ya que si se cuenta con requisitos tan altos y un procedimiento más complejo que el actual, se desincentivaría aún más su uso, lo que pugna con lo que se pretende con este trabajo. Sin perjuicio de ello, consideramos errada una reflexión de ese tipo. El indulto es profundamente impopular y en desuso, no por tener un procedimiento antiguo o arcaico, sino porque las autoridades estatales están conscientes de que su aplicación puede traer aparejado el repudio social y, lo que es peor, la vulneración de Derechos Fundamentales o el atentado a una norma de Derecho Internacional imperativa e inderogable. Es precisamente esto lo que se evita con la propuesta que hemos presentado. Si podemos reglamentar la institución de una manera que se limiten a casos estrictamente necesarios y con un procedimiento actual y respetuoso del ordenamiento jurídico interno e internacional, le estamos imprimiendo un sello respetuoso y vigente a la institución, lo que no obsta en nada para su uso habitual y sin los perjuicios de que adolece su aplicación en la actualidad. El problema del indulto no son sus principios inspiradores, ni menos la antigüedad y el desuso de la institución, la verdadera barrera a ser superada es su potencial carácter vulneratorio y el ambiente de impotencia social que trae aparejada su aplicación. Si logramos superar dichas dificultades rescataremos el verdadero sentido de la gracia: el perdón y solidaridad.

\section{CONCLUSIONES}

Habiendo finalizado nuestro trabajo de investigación advertimos que, efectivamente, la institución del indulto particular necesita ser perfeccionada en orden a cumplir con los estándares de los actuales Estados de Derecho y con la normativa internacional pertinente, siendo ambos estrictamente protectores de los derechos esenciales que emanan de la naturaleza humana.

Una vez analizadas las ventajas y desventajas de la institución comprobamos que ésta no debe ser derogada por completo; lo que podría concluirse a simple vista como la mejor solución, sino que han de existir modificaciones en torno a ella, que más bien digan relación con un perfeccionamiento del instituto de manera que tenga armonía con un sistema jurídico moderno y más proteccionista, pudiendo erigirse como un instrumento jurídico que en la práctica efectivamente contribuya a transparentar el proceso.

En la búsqueda del perfeccionamiento del indulto alcanzamos la creación de una propuesta innovadora y que mejor responde a la necesidad de contar con una institución moderna que concilie armoniosamente una facultad discrecional 
con el control de la arbitrariedad. Además, guarda equilibrio con un sistema en donde deben existir contrapesos, al incluir instancias de fiscalización y revisión de actos que de no ser controlados dejan al arbitrio de unos pocos decisiones que podrían conculcar derechos fundamentales de una manera irreversible.

\section{Bibliografía CitAdA}

AleXY, Robert, (2001): Teoría de los derechos fundamentales, Centro de Estudios Políticos y Constitucionales (Madrid, España), pp. 610.

Bandieri, Luis María (2007): “Textos para la Amnistía. La Amnistía o fuerza del olvido de Carl Schmitt”, (fecha de consulta: 18 de octubre de 2010). Disponible en: http://www.scribd.com/doc/8977458/Luis-Maria-BandieriTextos-para-la-Amnistia.

BANDRÉs, José María (1992): El derecho fundamental al proceso debido y el Tribunal Constitucional (Pamplona, España, Editorial Aranzadi), pp. 683.

Carrasco, Sergio (1998): "Sobre los indultos particulares en Chile", en Revista Chilena de Derecho, (Número especial), pp. 143-147.

De Carreras, Francesc (2000): "El indulto en nuestro Estado de Derecho. A propósito de indultos. Textos diversos", (fecha de consulta: 05 de octubre de 2010). Disponible en: http://www.tommouhi.com/indultos.html

EsCRICHE, Joaquín (1851): Diccionario Razonado de Legislación y Jurisprudencia, (París, Editorial Librería de Rosa, Bouret y Cía.), pp. 1576.

Etcheberry, Alfredo (1977): Derecho Penal. Parte General. Tomo II, (Santiago de Chile, Editorial Jurídica de Chile), pp. 269.

FernándeZ, Miguel Ángel (2001): Principio constitucional de igualdad ante la ley. (Santiago, Editorial Jurídica ConoSur Ltda.), pp. 352.

GarCía, Jerónimo (2007): El Indulto Particular: Tratamiento y Control Jurisdiccional, (Madrid, Editorial Dijusa), pp. 180.

Germán, Mariano (2008): "El Indulto: una institución satisfactoria para algunos, y fuente de críticas para otros", [fecha de consulta: 13 de agosto de 2008]. Disponible en: http://www.diariolibre.com/noticias_det. php?id=183409

Iglesias, Juan (2008): Derecho Romano (Barcelona, Editorial Ariel S.A.), pp. 480.

Nogueira, Humberto (2006): "Los desafíos de la sentencia de la Corte Interamericana en el caso Almonacid Arellano", en Revista Ius et Praxis (Año 12, No 2), pp. 363-384. 
Pan, Jorge; Bardazano, Gianella; Camaño, Diego (2008): "Inconstitucionalidad de los Indultos por Crímenes de Lesa Humanidad”. Comentarios al Fallo Riveros, (fecha de consulta: 17 de noviembre de 2010). Disponible en: http://www. cdh.uchile.cl/anuario04/5-Seccion_Internacional/1 Pan_Bardazano_Camano/ JorgePan-GuianellaBardazano-DiegoCamano.pdf

Piñera, Sebastián (2010): "Indulto Bicentenario. Pensando en lo mejor para Chile", (fecha de consulta: 27 de septiembre de 2012). Disponible en: http://www. gobiernodechile.cl/noticias/2010/07/25/indulto-y-bicentenario-pensandoen-lo-mejor-para-chile.htm

Robles, Walter (2010). "El Indulto: La institución del perdón”, (fecha de consulta: 5 de octubre de 2010). Disponible en: http://www.scribd.com/doc/34304185/ El-Indulto-La-Institucion-Del-Perdon

RPP NOTICIAS (2010): "Alan García sí puede revocar el indulto a Crousillat, opinan" (fecha de consulta: 27 de septiembre de 2012). Disponible en http:// www.rpp.com.pe/detalle.php?nid=249207

VARGAS, Juan Enrique (1994): La Extinción de la Responsabilidad Penal, Segunda Edición, (Santiago de Chile, Editorial Jurídica ConoSur Ltda.), pp. 229.

\section{NORMAS JURÍDICAS CITADAS}

Convención de Viena sobre el Derecho de los Tratados, 23 de mayo de 1969.

Convención Interamericana para el cumplimiento de condenas penales en el extranjero, 9 de junio de 1993.

Convenio sobre traslado de personas condenadas, 21 de marzo de 1983.

Decreto No 225-1999, Tratado entre la República de Chile y la República Federativa del Brasil sobre Transferencia de Presos Condenados. Diario Oficial, 18 de marzo de 1999.

Decreto No 1.002, sobre Indulto. "Guerra antisubversiva, Personal militar comprendido en determinadas Causas del 06 de octubre de 1989". Publicado en Argentina, 10 de octubre de 1986.

Ley reguladora del ejercicio de la gracia de indulto en España, 18 junio de 1870.

Pacto de San José de Costa Rica, 22 de noviembre de 1979.

Pacto Internacional de Derechos Civiles y Políticos, 16 de diciembre de 1966.

Proyecto de Ley No 5.945, que deroga facultades presidenciales para otorgar indultos particulares, Boletín No 5561-07, de 13 de diciembre de 2007. 
Resolución Ministerial No 193-2007-JUS (Reglamento de la Comisión de Indulto y Derecho de Gracia por Razones Humanitarias y Conmutación de la Pena de Perú), Diario El Peruano, 14 junio 2007.

$$
\text { JURISPRUDENCIA CITADA }
$$

Jalilie Awapara (2007): Tribunal Constitucional de Perú, 18 diciembre 2007 (recurso de agravio constitucional). Disponible en: http://www.tc.gob.pe/ jurisprudencia/2008/04053-2007-HC.html 